\title{
Intermittent Divergent Squint
}

\author{
Smita Kapoor* \\ Department of paediatric ophthalmology and strabismus, Vision eye centre, New Delhi, India
}

*Corresponding author: Smita Kapoor, Department of paediatric ophthalmology and strabismus, Vision eye centre, New Delhi, India

Received Date: November 11, 2018

Published Date: November 19, 2018

\section{Introduction}

Intermittent exotropia $\mathrm{X}(\mathrm{T})$ has an estimated prevalence ranging from $0.43-1.7 \%$ [1]. IXT is the most prevalent type of exotropia and has been reported to be more prevalent in females. The strabismus is exacerbated when the child focuses on distant objects, is tired or daydreaming, and may be accompanied by monocular eyelid closure in bright sunlight (diplopia phobia). Symptoms include headaches, eyestrain, blurred vision and occasional double vision. The frequency with which $\mathrm{X}(\mathrm{T})$ deteriorates to constant exotropia is unclear. Intermittent exotropia is subdivided into 'basic' and 'distance' subtypes. Reports suggest that some cases improve over time, some remain stable and others deteriorate. X(T) may be associated with overaction of the inferior oblique muscle (Figure 1 \& 2) and lateral incomitance. A child with X(T) may develop amblyopia or loss of binocular vision. For this reason, a child's vision and strabismus should be regularly monitored. Options for management of $\mathrm{X}(\mathrm{T})$ include observation, orthoptic exercises to strengthen binocular single vision, occlusion, minus lenses, prisms and surgery.

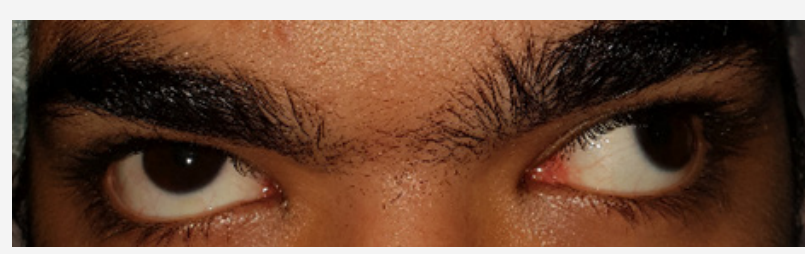

Figure 1: showing inferior oblique overaction in OD.

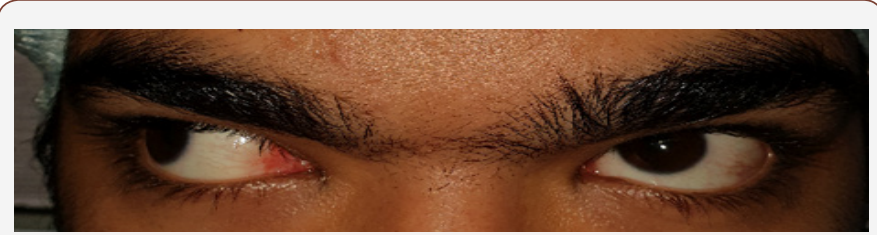

Figure 2: showing inferior oblique overaction in OS.

\section{Diagnostic Tests}

A diagnosis of $\mathrm{X}(\mathrm{T})$ is made using cover tests and by measuring the deviation using the prism cover test for both distance and near.
The basic type of $\mathrm{X}(\mathrm{T})$ shows a similar angle of deviation at distance and near. In divergence excess $\mathrm{X}(\mathrm{T})$ deviation measures 10 prism dioptres greater at distance than at near. Binocular vision is present in $\mathrm{X}(\mathrm{T})$ but with progression one eye may be suppressed. Stereopsis should be tested for both distance (Frisby Davis FD2) and near (TNO, Frisby, Randot). Abnormal distance stereopsis is an indicator of $\mathrm{X}(\mathrm{T})$ becoming manifest (Table 1 ).

Table 1: New Castle Score.

\begin{tabular}{|c|c|}
\hline Score & Component \\
\hline \multicolumn{2}{|l|}{ Home Control } \\
\hline 0 & Squint/Monocular eye closure never noticed \\
\hline 1 & $\begin{array}{l}\text { Squint/Monocular eye closure seen occasionally } \\
\text { (<50\% of time child observed) for distance }\end{array}$ \\
\hline 2 & $\begin{array}{l}\text { Squint/Monocular eye closure seen occasionally } \\
\text { ( }>50 \% \text { of time child observed) for distance }\end{array}$ \\
\hline 3 & $\begin{array}{l}\text { Squint/Monocular eye closure seen for distance \& } \\
\text { near fixation }\end{array}$ \\
\hline+ & \\
\hline \multicolumn{2}{|l|}{ Clinic control near } \\
\hline 0 & $\begin{array}{l}\text { Manifest only after cover test \& resumes fusion } \\
\text { without need for blinking or refixation }\end{array}$ \\
\hline 1 & Blink or refixate to control after CT \\
\hline 2 & $\begin{array}{l}\text { Manifest spontaneously or with any form of fusion } \\
\text { disruption without recovery }\end{array}$ \\
\hline+ & \\
\hline \multicolumn{2}{|l|}{$\begin{array}{l}\text { Clinic control } \\
\text { distance }\end{array}$} \\
\hline 0 & $\begin{array}{l}\text { Manifest only after cover test \& resumes fusion } \\
\text { without need for blinking or refixation }\end{array}$ \\
\hline 1 & Blink or refixate to control after CT \\
\hline 2 & $\begin{array}{l}\text { Manifest spontaneously or with any form of fusion } \\
\text { disruption without recovery }\end{array}$ \\
\hline $\begin{array}{c}\text { NCS total = Home }+ \\
\text { Clinic near }+ \text { Clinic } \\
\text { distance }\end{array}$ & \\
\hline
\end{tabular}




\section{Indications for Surgery}

The indications for surgery have been suggested to be a deviation, which is present $>50 \%$ of the time (home control) and which is poorly controlled on cover testing (office control). These indications have been quantified into a score-the Newcastle Control Score (NCS) for intermittent exotropia. The spontaneous cure rate is low for NCS $\geq 3$ thus surgery should be performed in such cases [2].

\section{Timing of Surgery}

Factors that influence the outcome of surgery are patients' age at onset of deviation, patients' age at surgery, interval between onset and surgery, refractive error, degree of anisometropia, visual acuity, presence of amblyopia, presence of an A- or a V-pattern, type of exotropia, existence of binocular single vision before surgery and the angle of deviation [3]. Non-surgical treatment may consist of the following.: Convergence exercises, part-time occlusion regimes (long-term success is unknown), minus lens therapy can be used to induce convergence. Prisms may be used but compliance may be difficult. Botulinum toxin injection into the lateral recti and biofeedback are lesser known options. Surgical treatment is performed to prevent deterioration to constant exotropia, to improve distance stereoacuity and for aesthetic considerations
[4]. Surgical options are medial rectus muscle resection and lateral rectus recession (unilateral surgery) or bilateral lateral rectus recession. Unilateral and bilateral surgery have been compared in which the former has been found to be more effective in correcting the strabismus.

\section{Acknowledgement}

None.

\section{Conflict of interest}

No conflict of interest.

\section{References}

1. Govindan M, Mohney BG, Diehl NN, Burke JP (2005) Incidence and types of childhood exotropia: a population-based study. Ophthalmology 112: 104-108.

2. Haggerty H, Richardson S, Hrisos S, Strong NP, Clarke MP (2004) The Newcastle Control Score: a new method of grading the severity of intermittent distance exotropia. Br J Ophthalmol 88(2): 233-235.

3. Awadein A, Eltanamly RM, Elshazly M (2014) Intermittent exotropia: relation between age and surgical outcome: a change-point analysis. Eye (Lond) 28(5): 587-93.

4. Buck D, Powell CJ, Rahi J, Jugnoo Rahi, Phillippa Cumberland, et al. (2012) The improving outcomes in intermittent exotropia study: outcomes at 2 years after diagnosis in an observational cohort. BMC Ophthalmol. 